\title{
Review Article \\ Borate Crystals for Nonlinear Optical and Laser Applications: A Review
}

\author{
R. Arun Kumar \\ Department of Basic Sciences (Physics), PSG College of Technology, Coimbatore 641 004, India \\ Correspondence should be addressed to R. Arun Kumar; rarunpsgtech@yahoo.com
}

Received 26 June 2012; Accepted 27 August 2012

Academic Editor: Veysel T. Yilmaz

Copyright ( $\odot 2013$ R. Arun Kumar. This is an open access article distributed under the Creative Commons Attribution License, which permits unrestricted use, distribution, and reproduction in any medium, provided the original work is properly cited.

The development of borate-based single crystals for laser and frequency conversion applications is reviewed. The basic idea behind nonlinear optics and the role of anionic groups in the borate crystals are summarized. The properties of borate crystals- $\mathrm{BBO}, \mathrm{LBO}$, $\mathrm{CBO}, \mathrm{KBBF}, \mathrm{SBBO}, \mathrm{CLBO}, \mathrm{YCOB}, \mathrm{GdCOB}, \mathrm{GdYCOB}, \mathrm{KAB}$ and $\mathrm{LCB}$ - are discussed. The growth and characterization of several rare earth-based borate crystals are mainly focused. Several borate crystals are grown from the melt techniques and a few crystals are grown adopting the flux technique. Many rare earth-based borate crystals are extensively used in device applications as they exhibit the frequency conversion ability along with high laser-induced damage tolerance.

\section{Introduction}

1.1. Demand for UV and Visible Radiations. The development of lasers has played a key role in the past five decades for the development of mankind in various fields and to reach several technological advancements. The demand for laser beams in the ultraviolet and visible regions is growing enormously. The laser beams in the UV and visible regions find applications in several industries, medical surgeries, data storage, optical communication, and entertainment purposes. Advances in semiconductor photolithography, for example, are creating demand for 158 and $193 \mathrm{~nm}$ coherent light sources, while emerging micromachining and material-processing applications also need deep-UV laser radiation. In addition, research scientists would like a widely tunable coherent light source down to $200 \mathrm{~nm}$ for laser spectroscopy and photochemical synthesis.

Although excimer lasers can emit some isolated wavelengths of coherent light in the UV and deep-UV spectral region with a high average output power, compact and efficient solid-state lasers with nonlinear optical (NLO) crystals in this spectral region are still needed. Important solid-state benefits include narrow bandwidth, improved beam quality, tunability, and relative ease of handling. The performance of solid-state lasers in the UV and deep-UV spectral regions depends heavily on efficient NLO crystals, such as the borate
deep-UV crystals that are being developed over the last two decades.

1.2. Emphasis of the Present Review. The recent developments in NLO borate crystals for the generation of high power visible and ultraviolet laser radiations are reviewed. The basic principles behind nonlinear optical materials are also dealt with. The classification of borate crystals based on the "anionic group theory" is discussed. Few important aspects involved in the growth of borate crystals and their properties are also reviewed and presented. The borate based NLO crystals are classified into three categories.

(i) $\mathrm{CBO}, \mathrm{LBO}$, and CLBO crystals

(ii) $\mathrm{KBBF}, \mathrm{SBBO}$, and $\mathrm{KAB}$ crystals

(iii) Rare-earth-based borate crystals

\section{Nonlinear Optics and Borate Crystals}

2.1. Basic Principles of Nonlinear Optics. The successful demonstration of lasers by Maiman and his coworkers in the year 1960 paved way for various scientific and technological advancements in the twentieth century [1]. A new field-nonlinear optics-came into being. Franken and his coworkers were the first to realize the nonlinear optical effect 
when they observed light at twice the frequency of a ruby laser $(\lambda=693.4 \mathrm{~nm})$ from a quartz crystal which was subjected to the ruby laser radiation. The practical observation of nonlinear optical phenomena would not have been observed if the lasers were not invented. This can be explained as follows. The field strengths of the conventional light sources used prior to the advent of lasers was of the order of $10^{3} \mathrm{~V} / \mathrm{m}$. But the interatomic field strengths lie in the range between $10^{7}$ and $10^{10} \mathrm{~V} / \mathrm{m}$. Hence, the conventional light sources are very less intense to affect the atomic fields to the extent of altering the optical parameters associated with it. The unique property of lasers, its coherence, helped in achieving radiations with the intensities of the order of $10^{10} \mathrm{~V} / \mathrm{m}$ feasible. Hence, lasers serve as useful and essential tool in the field of nonlinear optics and other related interesting phenomena such as Kerr effect, Pockels effect, second- or higher-harmonic generations, and so on.

The origin of NLO processes is the response of a nonlinear dielectric medium to an oscillating electric field. For example, when a dielectric material is subjected to an electromagnetic (e.m) radiation, the propagation of the e.m wave through the material produces changes in the spatial and temporal distribution of electric charges due to the interaction between the e.m wave, electrons, and atoms. This perturbation creates electric dipoles whose manifestation is macroscopic polarization $(P)$. When the applied electric field $(E)$ is very small, the induced polarization can be expressed as,

$$
P=\varepsilon_{0} \chi^{(1)} E,
$$

where $\varepsilon_{0}$ is the permittivity of free space $\left(\varepsilon_{0}=8.854 \times\right.$ $10^{-12} \mathrm{C}^{2} \mathrm{~s}^{2} / \mathrm{kg} \mathrm{m}^{3}$ ) and $\chi^{(1)}$ is the linear susceptibility term which is responsible for the optical properties such as absorption, index of refraction, dispersion, and birefringence of the medium. When the applied electric field is highly intense and comparable to the interatomic field, the induced polarization is given by,

$$
P=\varepsilon_{0}\left(\chi^{(1)} E+\chi^{(2)} E \cdot E+\chi^{(3)} E \cdot E \cdot E+\cdots\right),
$$

where $\chi^{(2)}, \chi^{(3)}$ are the second- and the third-order nonlinear susceptibilities and their magnitude decreases as their order increases $\left(\chi^{(1)}: \chi^{(2)}: \chi^{(3)}=1: 10^{-8}: 10^{-16}\right)$. The second order susceptibility term $\left(\chi^{(2)}\right)$ gives rise to second-harmonic generation, frequency mixing and parametric generation and the third order susceptibility term $\left(\chi^{(3)}\right)$ is responsible for the third harmonic generation, Stimulated Raman scattering, optical bistability, and phase conjugation.

For the purpose of reliable laser frequency conversion, NLO crystals with the following properties are desired: large NLO coefficient, moderate birefringence, small walk-off effect, large angular, spectral and temperature bandwidths, wide transparency in the wavelength of interest, high laserinduced damage threshold, ease of growth, low material cost, good chemical stability, and good mechanical stability.

Till 1975, extensive research on NLO crystals based on the $\mathrm{P}-\mathrm{O}, \mathrm{I}-\mathrm{O}$, and $\mathrm{Nb}-\mathrm{O}$ bonds were carried out. The widely studied $\mathrm{NLO}$ crystals include $\mathrm{KDP}\left(\mathrm{KH}_{2} \mathrm{PO}_{4}\right), \mathrm{LN}$
$\left(\mathrm{LiNbO}_{3}\right), \mathrm{LiIO}_{3}$, and so forth as they fulfill the above listed requirements to a good extent. With the advent of potassium pentaborate, $\mathrm{KB}_{5} \mathrm{O}_{8} \cdot 4 \mathrm{H}_{2} \mathrm{O}$, crystal in the year 1975 , tremendous attention was directed to grow boratebased crystals for frequency conversion purposes.

2.2. Nonlinear Optical Borate Crystals. The large family of borate compounds is a suitable chemical playground now adopted by many materials scientists, because the extremely wide variability of borate crystal chemistry allows the creation of various different structure types [2]. Furthermore, among all the borate structures reported till date, 36\% are noncentrosymmetric, while among the reported inorganic crystal structures there are in total only $15 \%$ of noncentrosymmetic structure [3].

Borate crystals are superior in UV applications to other commonly used NLO materials such as potassium di hydrogen phosphate (KDP) or lithium niobate (LN) because of their high transmittance at wavelengths down to $155 \mathrm{~nm}$ combined with higher damage threshold. A comparison of selected NLO materials is given in the Table 1. The first borate crystal described for UV light generation was potassium pentaborate $\left(\mathrm{KB}_{5} \mathrm{O}_{8} \cdot 4 \mathrm{H}_{2} \mathrm{O}\right)$ [4]. However, intense research work on borate crystals was initiated only after the development of $\beta-\mathrm{BaB}_{2} \mathrm{O}_{4}(\mathrm{BBO})$ and $\mathrm{LiB}_{3} \mathrm{O}_{5}$ ( $\left.\mathrm{LBO}\right)$. There are several borate crystals available today which cater the need of optical industry [5-10].

The optical properties of borate crystals can be related to their molecular structure. A few borate crystals are mentioned in the Table 1 as examples. These crystals are constructed from the three basic structure units: $\left(\mathrm{B}_{3} \mathrm{O}_{6}\right)^{3-}$, $\left(\mathrm{B}_{3} \mathrm{O}_{7}\right)^{5-}$, and $\left(\mathrm{BO}_{3}\right)^{3-}$ anionic groups. The $\left(\mathrm{B}_{3} \mathrm{O}_{6}\right)^{3-}$, $\left(\mathrm{B}_{3} \mathrm{O}_{7}\right)^{5-}$, and $\left(\mathrm{BO}_{3}\right)^{3-}$ anionic groups are shown in Figure 1. A model called the "anionic group theory" was designed by Chen and his coworkers and is used to understand the relation between composition, structure of borate materials, and the related NLO properties [11].

Due to the planar hexagonal structure of the $\left(\mathrm{B}_{3} \mathrm{O}_{6}\right)^{3-}$ anionic group, borate crystals constructed from this basic unit have greater $\chi^{(2)}$ compared to crystals composed of $\left(\mathrm{B}_{3} \mathrm{O}_{7}\right)^{5-}$ and $\left(\mathrm{BO}_{3}\right)^{3-}$ anionic groups. Thus in terms of NLO coefficients, the $\left(\mathrm{B}_{3} \mathrm{O}_{6}\right)^{3-}$ group is the most suitable as the basic structure unit of NLO borate crystals followed by $\left(\mathrm{B}_{3} \mathrm{O}_{7}\right)^{5-}$ group and then $\left(\mathrm{BO}_{3}\right)^{3-}$ group. However, the $\mathrm{UV}$ absorption edge of the borate crystals constructed from the $\left(\mathrm{B}_{3} \mathrm{O}_{6}\right)^{3-}$ group occurred at a longer wavelength (e.g., $\mathrm{BBO})$ when compared to those constructed from $\left(\mathrm{B}_{3} \mathrm{O}_{7}\right)^{5-}$ group (e.g., $\mathrm{LBO}, \mathrm{CBO}, \mathrm{CLBO}$ ). Calculations showed that $\pi$-conjugated orbitals of planar $\left(\mathrm{B}_{3} \mathrm{O}_{6}\right)^{3-}$ tend to shift the $\mathrm{UV}$ absorption edge toward the red. As one of the boron atoms in $\left(\mathrm{B}_{3} \mathrm{O}_{6}\right)^{3-}$ changed from trigonal to tetrahedral coordination, thereby forming nonplanar $\left(\mathrm{B}_{3} \mathrm{O}_{7}\right)^{5-}$ groups, the $\pi$-conjugated orbital system is weakened, as in the case of $\mathrm{LBO}$ and $\mathrm{CBO}$ and the UV absorption edge shifts to 160-170 nm. Both CBO and LBO are constructed from a continuous network of nonplanar $\left(\mathrm{B}_{3} \mathrm{O}_{7}\right)^{5-}$ groups with interstitial cesium and lithium cations, respectively. Based on 
TABLE 1: Selected properties of few borate crystals.

\begin{tabular}{lcccc}
\hline Crystals & Space group & Transparency range $(\mathrm{nm})$ & Shortest SHG $(\mathrm{nm})$ & Basic structure unit \\
\hline$\beta-\mathrm{BaB}_{2} \mathrm{O}_{4}(\mathrm{BBO})$ & $\mathrm{R} \mathrm{3c}$ & $190-3300$ & 205 & $\mathrm{~B}_{3} \mathrm{O}_{6}$ \\
$\mathrm{LiB}_{3} \mathrm{O}_{5}(\mathrm{LBO})$ & $\mathrm{Pnn} 2_{1}$ & $160-2600$ & 277 & $\mathrm{~B}_{3} \mathrm{O}_{7}$ \\
$\mathrm{CsB}_{3} \mathrm{O}_{5}(\mathrm{CBO})$ & $\mathrm{P} 2_{1} 2_{1} 2_{1}$ & $167-3400$ & 185 & $\mathrm{~B}_{3} \mathrm{O}_{7}$ \\
$\mathrm{KBe}_{2} \mathrm{BO}_{3} \mathrm{~F}_{2}(\mathrm{KBBF})$ & $\mathrm{R} 32$ & $155-3660$ & 200 & $\mathrm{BO}_{3}$ \\
$\mathrm{Sr}_{2} \mathrm{Be}_{2} \mathrm{BO}_{7}(\mathrm{SBBO})$ & $\mathrm{P} 6_{3}$ & $155-3780$ & 237 & $\mathrm{BO}_{3}$ \\
$\mathrm{CsLiB}_{6} \mathrm{O}_{10}(\mathrm{CLBO})$ & $142 \mathrm{~d}$ & $180-2750$ & $\mathrm{~B}_{3} \mathrm{O}_{7}$ \\
\hline
\end{tabular}

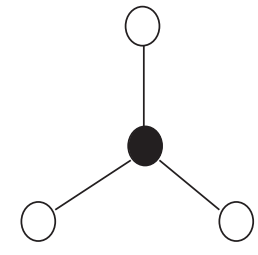

(a)

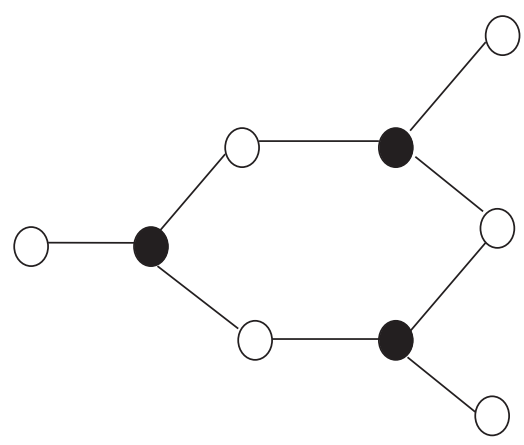

(b)

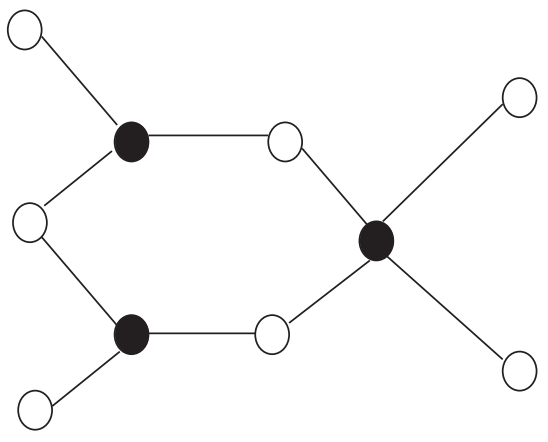

(c)

Figure 1: Basic structure units of (a) $\mathrm{BO}_{3}$ (b) $\mathrm{B}_{3} \mathrm{O}_{6}$ (c) $\mathrm{B}_{3} \mathrm{O}_{7}$ borates (dark circles represent boron and bright circles represent oxygen atoms).

the absorption edge, therefore, $\left(\mathrm{B}_{3} \mathrm{O}_{7}\right)^{5-}$ group is ideal as the basic structural unit of deep-UV NLO materials. Likewise, if the dangling bonds of the three terminated oxygen atoms of $\left(\mathrm{BO}_{3}\right)^{3-}$ groups are interlinked with cations, an absorption edge appearing at wavelengths as short as $155 \mathrm{~nm}$ is also feasible as in the cases with KBBF and SBBO.

\section{NLO Borate Crystals}

3.1. $C B O, L B O$, and CLBO Crystals. There is a tremendous amount of work on $\mathrm{CsB}_{3} \mathrm{O}_{5}(\mathrm{CBO})$ and $\mathrm{LiB}_{3} \mathrm{O}_{5}$ (LBO) crystals by flux techniques for the fourth- and the fifthharmonic generations of $\mathrm{Nd}$ : YAG lasers. Another derivative of $\mathrm{LBO}$ is $\mathrm{CsB}_{3} \mathrm{O}_{5}$ (CBO). $\mathrm{CBO}$ compound melts congruently at $842^{\circ} \mathrm{C}$. Crystals with dimensions of $20 \mathrm{~mm}$ in diameter and $30 \mathrm{~mm}$ in length were grown with the pulling rate of $8 \mathrm{~mm} /$ day. In general, a good NLO crystal that can generate deep-UV light effectively is required to have a birefringence between that of BBO $(\Delta n=0.12$ at $\lambda=1064 \mathrm{~nm})$ and LBO $(\Delta n$ $=0.04$ at $\lambda=1064 \mathrm{~nm}$ ). This property allows the expansion of the phase matching range for SHG at a reasonably low walkoff effect and significantly large phase-matching bandwidths. The earlier mentioned CLBO crystal has $\Delta n=0.052$ at $\lambda$ $=1064 \mathrm{~nm}$ and hence, it is widely used for deep-UV light conversion. Thus several NLO crystals like CLBO that possess a birefringence between $\mathrm{BBO}$ and CLBO are desired.

$\mathrm{CsLiB}_{5} \mathrm{O}_{10}(\mathrm{CLBO})$ crystals, which are the structural derivatives of LBO crystals, are grown in larger dimensions from their melts. Very large CLBO single crystals with the dimensions of $140 \times 110 \times 110 \mathrm{~mm}^{3}$ with good optical quality were grown and reported [12].

3.2. $K B B F, S B B O$, and $K A B$ Crystals. Isostructural borate crystals of $\mathrm{SrB}_{4} \mathrm{O}_{7}$ and $\mathrm{PbB}_{4} \mathrm{O}_{7}$, both of which belong to the orthorhombic crystal system are grown from their melts. Large single crystals of $\mathrm{PbB}_{4} \mathrm{O}_{7}$ were grown by the Czochralski technique from a melt with a slight excess of $\mathrm{PbO}$ to lower the viscosity of the melt at $774^{\circ} \mathrm{C}$. Seed crystals with the [100] or [001] orientations were preferred for single crystal growth. Growth runs, with a cooling rate of $0.7^{\circ} \mathrm{C} /$ day and a pulling rate of $4 \mathrm{~mm} /$ day have yielded single crystals with $20 \times 28 \times 55 \mathrm{~mm}^{3}$ dimensions. In the similar manner, single crystals of $\mathrm{SrB}_{4} \mathrm{O}_{7}$ were grown from its stoichiometric melt at $994^{\circ} \mathrm{C}$. Single crystals with $25 \mathrm{~mm}$ diameter and $20 \mathrm{~mm}$ length were grown using pulling rates of $2 \mathrm{~mm}$ /day with the crystal rotation of $20 \mathrm{rpm}$.

Intense research on the incongruently melting borate crystals is also in progress. Due to the fact that a few incongruently melting borate materials are transparent down to vacuum-UV region, single crystal growth of these materials is undertaken. The family $\mathrm{MBe}_{2} \mathrm{BO}_{3} \mathrm{~F}_{2}$, with $\mathrm{M}=\mathrm{Na}, \mathrm{K}$, is an example of a structure type with isolated $\left[\mathrm{BO}_{3}\right]$ triangles, crystallizing in the noncentrosymmetric space group R32. The potassium compound $\mathrm{KBe}_{2} \mathrm{BO}_{3} \mathrm{~F}_{2}$ (KBBF) was first 
TABLE 2: Comparison between RECOB crystals.

\begin{tabular}{|c|c|c|c|}
\hline Properties & YCOB & GdCOB & LCOB \\
\hline \multirow{3}{*}{ Unit cell parameters } & $a=8.04 \AA$ & $a=8.09 \AA$ & $a=8.16 \AA$ \\
\hline & $b=15.95 \AA$ & $b=16.01 \AA$ & $b=16.08 \AA$ \\
\hline & $c=3.51 \AA$ & $c=3.55 \AA$ & $c=3.63 \AA$ \\
\hline \multirow{2}{*}{ Bond angle } & $\alpha=\gamma=90^{\circ}$ & $\alpha=\gamma=90^{\circ}$ & $\alpha=\gamma=90^{\circ}$ \\
\hline & $\beta=101.19^{\circ}$ & $\beta=101.27^{\circ}$ & $\beta=101.3^{\circ}$ \\
\hline Crystal system & Monoclinic & Monoclinic & Monoclinic \\
\hline Space group & $C_{m}$ & $C_{m}$ & $C_{m}$ \\
\hline Hygroscopicity & Nonhygroscopic & Nonhygroscopic & Nonhygroscopic \\
\hline Transparency range & $220-3600 \mathrm{~nm}$ & $320-2700 \mathrm{~nm}$ & Above $210 \mathrm{~nm}$ \\
\hline Melting point & $1510^{\circ} \mathrm{C}$ & $1480^{\circ} \mathrm{C}$ & $1410^{\circ} \mathrm{C}$ \\
\hline
\end{tabular}

synthesized in the year 1968. These crystals were grown from flux melts with $\mathrm{KBF}_{4}$ and $\mathrm{BeO}$. The plate-like crystals with the dimensions of $10 \times 10 \times 0.3 \mathrm{~mm}^{3}$ were reported.

Improvement of the NLO properties by increasing the number of $\mathrm{NLO}$ active $\left[\mathrm{BO}_{3}\right]$ groups per unit volume of the crystal structure was attempted by creating $\mathrm{Sr}_{2} \mathrm{Be}_{2} \mathrm{~B}_{2} \mathrm{O}_{7}$ (SBBO). These crystals exhibit the hexagonal crystal system and were grown by the TSSG technique. These crystals are grown by slow cooling with the cooling rate of $1-2^{\circ} \mathrm{C} /$ day. Crystals with the dimensions of $7 \times 7 \times 3 \mathrm{~mm}^{3}$ with good optical quality are obtained and reported. SBBO $(\Delta n=0.062$ at $\lambda=589 \mathrm{~nm})$ and KBBF crystals $(\Delta n=0.072$ at $\lambda=589 \mathrm{~nm})$ are attractive candidates in this aspect. However, because of the weak binding between the layered structural units, $\mathrm{KBBF}$ is difficult to grow and is mechanically fragile [13]. The SBBO has strong covalent bonds between beryllium atoms and oxygen atoms in adjacent layers. This makes SBBO mechanically stronger and relatively easy to grow compared to KBBF. However, beryllium is toxic, which makes crystal growth inconvenient. Thus, it is important that the Be atoms in SBBO be replaced by a nontoxic element. Sasaki and his coworkers had attempted to replace the $\left(\mathrm{BeO}_{4}\right)^{6-}$ with $\left(\mathrm{AlO}_{4}\right)^{5-}$ and had replaced $\mathrm{Sr}^{2+}$ with $\mathrm{M}^{+}\left(\mathrm{M}^{+}=\mathrm{Li}^{+}, \mathrm{Na}^{+}, \mathrm{K}^{+}\right.$, $\mathrm{Rb}^{+}$and $\left.\mathrm{Cs}^{+}\right)$according to the concept of ionic compensation $\left(\mathrm{Al}^{3+}+\mathrm{K}^{+} \rightarrow \mathrm{Be}^{2+}+\mathrm{Sr}^{2+}\right)$. In this way, potassium aluminum borate crystal with the chemical formula $\mathrm{K}_{2} \mathrm{Al}_{2} \mathrm{~B}_{2} \mathrm{O}_{7}$ (KAB) was discovered. $\mathrm{KAB}$ has the spatial arrangement similar to that of SBBO.

The structure of the KAB crystal is trigonal with the P321 space group. The lattice parameters of the crystal are $a=b=$ $8.5657 \AA, c=8.463 \AA, V=537.7 \AA^{3}$, and $Z=3$ [14]. The KAB crystals are grown from flux technique. Different fluxes such as $\mathrm{B}_{2} \mathrm{O}_{3}, \mathrm{~K}_{2} \mathrm{CO}_{3}$, and $\mathrm{K}_{2} \mathrm{CO}_{3}-\mathrm{B}_{2} \mathrm{O}_{3}$, alkali halides such as $\mathrm{KF}$ and $\mathrm{NaF}$ were used for the growth of $\mathrm{KAB}$ crystals and are reported. The KAB crystal is transparent from 180-3600 nm. The thermal property of the KAB crystal is also studied. The linear thermal expansion coefficient of the KAB crystal along the $x, y$, and $z$ directions are very lesser. The specific heat values of $\mathrm{KAB}$ crystal at $47.6^{\circ} \mathrm{C}$ and $294.6^{\circ} \mathrm{C}$ are $1.0084 \mathrm{~J} / \mathrm{g}{ }^{\circ} \mathrm{C}$ and $1.39 \mathrm{~J} / \mathrm{g}^{\circ} \mathrm{C}[15]$.
3.3. Rare-Earth-Based Borate Crystals. Borate crystals are not only employed for frequency conversion applications but also as self-frequency doubling (SFD) active laser sources in the recent years. Rare-earth-based borate crystals are employed both for NLO and SFD applications.

3.4. Huntite Family Crystals. The families of borate crystals with the general chemical formula, $\mathrm{RAl}_{3}\left(\mathrm{BO}_{3}\right)_{4}$ with $\mathrm{R}=\mathrm{Y}$, $\mathrm{Nd}, \mathrm{Sm}, \mathrm{Eu}, \mathrm{Tb}, \mathrm{Dy}, \mathrm{Er}$, and $\mathrm{RX}_{3}\left(\mathrm{BO}_{3}\right)_{4}$ with $\mathrm{R}=\mathrm{Gd}, \mathrm{Sm}, \mathrm{X}=$ $\mathrm{Cr}, \mathrm{Al}$ are termed as "huntite" family crystals. The emissions of sharp bright lines from these crystals were observed. These crystals are chemically stable, nonhygroscopic, and have high hardness. These crystals melt incongruently and are grown from flux methods only. All these crystals are trigonal with the space group R32. The widely studied huntite-type borate crystal is $\mathrm{YAl}_{3}\left(\mathrm{BO}_{3}\right)_{4}$ (YAB) [16]. These crystals are doped with $\mathrm{Er}, \mathrm{Nd}$, and $\mathrm{Yb}$ ions for making them as SFD crystals. It is commonly grown by top seeded solution growth (TSSG) method.

$\mathrm{YAB}$ is a noncentrosymmetric crystal and as early as in 1974 , it was reported as a very effective second-harmonic generating material. Furthermore, owing to its good chemical stability and the possibility of substituting $\mathrm{Y}^{3+}$ ions with other lanthanide ions, namely $\mathrm{Nd}^{3+}, \mathrm{Yb}^{3+}$, and $\mathrm{Er}^{3+}$, it is a good material for laser applications. The nonlinear optical properties of this material along with lasing properties led to the fabrication of numerous systems generating red, green, and blue lights due to self-frequency doubling effect [17]. They also possess relatively large two-photon absorption. These compounds are promising candidate as second- and third-order optical materials [18]. At the same time they are good matrices for different rare-earth ions [19, 20]. Reports are also available on the $\mathrm{Nd}^{3+}-, \mathrm{Tb}^{3+}-, \mathrm{Yb}^{3+}$-, and $\mathrm{Er}^{3+}$-doped YAB crystals [21-23].

Further, in the family of borate crystals with huntite structure, research on crystals such as $\mathrm{NdAl}_{3}\left(\mathrm{BO}_{3}\right)_{4}(\mathrm{NAB})$, $\mathrm{ErAl}_{3}\left(\mathrm{BO}_{3}\right)_{4}(\mathrm{ErAB})$, or $\mathrm{YbAl}_{3}\left(\mathrm{BO}_{3}\right)_{4}(\mathrm{YbAB})$ is carried out in the present years [24]. The melting points of these materials are below $1300^{\circ} \mathrm{C}$. These crystals are grown by flux techniques and are mainly employed in SFD purposes. 
3.5. Rare-Earth Calcium Oxy Borate (RECOB) Crystals. The first member of the rare-earth calcium oxy borate (RECOB) crystals with the chemical composition of $\mathrm{RECa}_{4} \mathrm{O}\left(\mathrm{BO}_{3}\right)_{3}$ $(\mathrm{RE}=\mathrm{Sm})$ was synthesized by Khamaganova and his coworkers in the year 1991 [25]. Later intense work on the growth and characterization of this family of crystals with various rare-earth elements such as $\mathrm{La}, \mathrm{Nd}, \mathrm{Gd}, \mathrm{Er}$, and $\mathrm{Y}$ were carried out and reported. The RECOB family of crystals appears to be attractive candidates for NLO applications as they possess the noncentrosymmetric structure which is an essential parameter for any NLO material. Widely studied RECOB crystals include YCOB, GdCOB, and LCOB crystals. The RECOB crystals with the rare-earth ions with electronic configurations $4 \mathrm{f}^{n}, n \neq 0,7,14$ give rise to electronic transitions in the visible region that would interfere with the expected NLO properties.

The RECOB crystals melt congruently and were conventionally grown by the Czochralski and Bridgman techniques of crystal growth. The melting temperatures of the RECOB crystals increase with a decrease in the ionic radii of the rareearth ion present in it [26]. Accordingly, the melting points of LCOB, GdCOB, and YCOB single crystals are 1410, 1480, and $1510^{\circ} \mathrm{C}$, respectively [27].

The RECOB single crystals exhibit the monoclinic crystal structure with the $\mathrm{C}_{m}$ space group. They are biaxial crystals. These crystals offer the advantage in providing suitable sites for doping them with "laser-active" ions, since the widely used "laser-active" ions such as neodymium, erbium, and ytterbium have similar ionic radii and occur in the trivalent state as that of the rare-earth ion present in the RECOB crystals $[28,29]$. The flux growth of yttrium calcium oxy borate (YCOB) single crystals by flux technique was also carried out by our group earlier and reported [30]. The growth and characterization of pure and $\mathrm{Nd}^{3+}$ present lanthanum calcium oxy borate (LCOB) were performed and reported [31]. A comparison between YCOB, LCOB, and GdCOB crystals are summarized in Table 2.

3.6. Rare Earth Calcium Borate (RCB) Crystals. Another emerging borate-based crystal family is rare-earth calcium borate (RCB) crystals, with the general chemical formula $\mathrm{R}_{2} \mathrm{CaB}_{10} \mathrm{O}_{19}$ ( $\mathrm{R}$ represents rare-earth element). In this series of crystals, only crystal growth of pure and doped lanthanum calcium borate (LCB) are performed and reported in literature. There are no reports available on any other materials in the RCB family of crystals. The LCB crystal is reported to be insensitive to moisture, has high hardness (6.5 mhos), and is transparent from $180 \mathrm{~nm}$ to $3300 \mathrm{~nm}$. Moreover, the laser damage threshold (LDT) value of the LCB crystal is also very high $\left(11.5 \mathrm{GW} / \mathrm{cm}^{2}\right.$ for $1064 \mathrm{~nm}, 8 \mathrm{~ns}$ radiation) [32]. Various reports on "laser-active-" ion-doped LCB crystals are also available in literature [33].

\section{Conclusion}

Growth and material characteristics of several borate-based single crystals were discussed. Borate crystals are grown from melt and flux techniques. Anionic group theory plays an essential theory for selecting borate materials for nonlinear optical applications. Several borate-based crystals act as desirable host materials for fabricating lasers. Borate crystals offer themselves as suitable candidates for both nonlinear optical and laser applications.

\section{Acknowledgment}

The author is thankful to the Science and Engineering Research Board (SERB), Department of Science and Technology (DST), Government of India, for awarding Major Research Project to work on borate-based single crystals.

\section{References}

[1] T. H. Maiman, "Stimulated optical radiation in Ruby," Nature, vol. 187, no. 4736, pp. 493-494, 1960.

[2] D. Xue, K. Betzler, H. Hesse, and D. Lammers, "Nonlinear optical properties of borate crystals," Solid State Communications, vol. 114, no. 1, pp. 21-25, 2000.

[3] G. Aka and A. Brenier, "Self-frequency conversion in nonlinear laser crystals," Optical Materials, vol. 22, no. 2, pp. 89-94, 2003.

[4] C. F. Dewey, W. R. Cook, R. T. Hodgson, and J. J. Wynne, "Frequency doubling in $\mathrm{KB}_{5} \mathrm{O}_{8}-4 \mathrm{H}_{2} \mathrm{O}$ and $\mathrm{NH}_{4} \mathrm{~B}_{5} \mathrm{O}_{8}-4 \mathrm{H}_{2} \mathrm{O}$ to 217.3 nm," Applied Physics Letters, vol. 26, pp. 714-717, 1975.

[5] V. T. Adamiv, Y. V. Burak, I. V. Kityk, J. Kasperczyk, R. Smok, and M. Czerwiński, "Nonlinear optical properties of $\mathrm{Li}_{2} \mathrm{~B}_{4} \mathrm{O}_{7}$ single crystals doped with potassium and silver," Optical Materials, vol. 8, no. 3, pp. 207-213, 1997.

[6] A. Majchrowski, I. V. Kityk, and J. Ebothé, "Influence of YAB: $\mathrm{Cr}^{3+}$ nanocrystallite sizes on two-photon absorption of YAB: $\mathrm{Cr}^{3+}$," Physica Status Solidi B, vol. 241, no. 13, pp. 3047-3055, 2004.

[7] M. Ghotbi, M. Ebrahim-Zadeh, A. Majchrowski, E. Michalski, and I. V. Kityk, "High-average-power femtosecond pulse generation in the blue using $\mathrm{BiB}_{3} \mathrm{O}_{6}$," Optics Letters, vol. 29, no. 21, pp. 2530-2532, 2004.

[8] M. Ghotbi, Z. Sun, A. Majchrowski, E. Michalski, and I. V. Kityk, "Efficient third harmonic generation of microjoule picosecond pulses at $355 \mathrm{~nm}$ in $\mathrm{BiB}_{3} \mathrm{O}_{6}$," Applied Physics Letters, vol. 89, no. 17, Article ID 173124, 3 pages, 2006.

[9] V. Petrov, M. Ghotbi, O. Kokabee et al., "Femtosecond nonlinear frequency conversion based on $\mathrm{BiB}_{3} \mathrm{O}_{6}$," Laser and Photonics Reviews, vol. 4, no. 1, pp. 53-98, 2010.

[10] I. V. Kityk and A. Majchrowski, "Second-order non-linear optical effects in $\mathrm{BiB}_{3} \mathrm{O}_{6}$ glass fibers," Optical Materials, vol. 26, pp. 33-37, 2004.

[11] C. Chen, Laser Science and Technical International Handbook, Harwood, New York, NY, USA, 1993.

[12] T. Sasaki, Y. Mori, M. Yoshimura, Y. K. Yap, and T. Kamimura, "Recent development of nonlinear optical borate crystals: key materials for generation of visible and UV light," Materials Science and Engineering R, vol. 30, no. 1-2, pp. 1-54, 2000.

[13] C. Chen, Y. Wang, B. Wu, K. Wu, W. Zeng, and L. Yu, "Design and synthesis of an ultraviolet-transparent nonlinear optical crystal $\mathrm{Sr}_{2} \mathrm{Be}_{2} \mathrm{~B}_{2} \mathrm{O}_{7}$," Nature, vol. 373, pp. 322-324, 1995.

[14] Z. G. Hu, T. Higashiyama, M. Yoshimura, Y. K. Yap, Y. Mori, and T. Sasaki, "A new nonlinear optical borate crystal $\mathrm{K}_{2} \mathrm{Al}_{2} \mathrm{~B}_{2} \mathrm{O}_{7}$ (KAB)," Japanese Journal of Applied Physics, vol. 37, pp. 1093-1094, 1998. 
[15] C. Zhang, J. Wang, X. Cheng et al., "Growth and properties of $\mathrm{K}_{2} \mathrm{Al}_{2} \mathrm{~B}_{2} \mathrm{O}_{7}$ crystal," Optical Materials, vol. 23, no. 1-2, pp. 357-362, 2003.

[16] A. H. Reshak, S. Auluck, A. Majchrowski, and I. V. Kityk, "Band structure features of nonlinear optical yttrium aluminium borate crystal," Solid State Sciences, vol. 10, no. 10, pp. 1445-1448, 2008.

[17] D. Jaque, J. Capmany, and S. Qarcia, "Red, green, and blue laser light from a single $\mathrm{Nd}: \mathrm{YAl}_{3}\left(\mathrm{BO}_{3}\right)_{4}$ crystal based on laser oscillation at $1.3 \mu \mathrm{m}$," Applied Physics Letters, vol. 75, pp. 325-3327, 1999.

[18] A. Majchrowski, J. Ebothé, I. Fuks-Janczarek, M. MakowskaJanusik, B. Sahraoui, and I. V. Kityk, "Two-photon absorption in YAB:Cr ${ }^{3+}$ nanocrystallites," Optical Materials, vol. 27, no. 4, pp. 675-678, 2005.

[19] G. Dominiak-Dzik, W. Ryba-Romanowski, L. Kovács, and E. Beregi, "Effect of temperature on luminescence and VUV to visible conversion in the $\mathrm{YAl}_{3}\left(\mathrm{BO}_{3}\right)_{4}: \mathrm{Dy}^{3+}$ (YAB:Dy) crystal," Radiation Measurements, vol. 38, no. 4-6, pp. 557-561, 2004.

[20] W. You, Y. Lin, Y. Chen, Z. Luo, and Y. Huang, "Growth and spectroscopic properties of $\mathrm{Er}^{3+}$ single doped and $\mathrm{Er}^{3+}-\mathrm{Yb}^{3+} \mathrm{co}-$ doped $\mathrm{YAl}_{3}\left(\mathrm{BO}_{3}\right)_{4}$ crystals," Journal of Crystal Growth, vol. 270, no. 3-4, pp. 481-485, 2004.

[21] D. Jaque, J. Capmany, F. Molero, Z. D. Luo, and J. García Sole, "Up-conversion luminescence in the $\mathrm{Nd}^{3+}: \mathrm{YAB}$ self frequency doubling laser crystal," Optical Materials, vol. 10, no. 3, pp. 211-217, 1998.

[22] J. Li, J. Wang, X. Cheng, X. Hu, X. Wang, and S. Zhao, "Growth, optical properties and defects of Tb: $\mathrm{YAl}_{3}\left(\mathrm{BO}_{3}\right)_{4}$ crystal," Materials Letters, vol. 58, no. 6, pp. 1096-1099, 2004.

[23] J. Li, J. Wang, H. Tan et al., "Growth and optical properties of Er,Yb: $\mathrm{YAl}_{3}\left(\mathrm{BO}_{3}\right)_{4}$ crystal," Materials Research Bulletin, vol. 39, no. 9, pp. 1329-1334, 2004.

[24] N. I. Leonyuk, V. V. Maltsev, E. A. Volkova et al., "Crystal growth and laser properties of new $\mathrm{RAl}_{3}\left(\mathrm{BO}_{3}\right)_{4}(\mathrm{R}=\mathrm{Yb}, \mathrm{Er})$ crystals," Optical Materials, vol. 30, no. 1, pp. 161-163, 2007.

[25] T. N. Khamaganova, V. K. Trunov, and B. F. Dzhurinskii, "Crystal structure of calcium samarium oxyborate $\mathrm{Sm}_{2} \mathrm{Ca}_{8} \mathrm{O}_{2}\left(\mathrm{BO}_{3}\right)_{6}$," Russian Journal of Inorganic Chemistry, vol. 36, pp. 855-857, 1991.

[26] H. Nakao, M. Nishida, T. Shikida, H. Shimizu, H. Takeda, and T. Shiosaki, "Growth and SAW properties of rare-earth calcium oxoborate crystals," Journal of Alloys and Compounds, vol. 408-412, pp. 582-585, 2006.

[27] D. Vivien, G. Aka, A. Kahn-Harari et al., "Crystal growth and optical properties of rare earth calcium oxoborates," Journal of Crystal Growth, vol. 237-239, pp. 621-628, 2002.

[28] F. Mougel, G. Aka, A. Kahn-Harari, H. Hubert, J. M. Benitez, and D. Vivien, "Infrared laser performance and self-frequency doubling of $\mathrm{Nd}^{3+}: \mathrm{Ca}_{4} \mathrm{GdO}\left(\mathrm{BO}_{3}\right)_{3}$ (Nd:GdCOB)," Optical Materials, vol. 8, no. 3, pp. 161-173, 1997.

[29] A. Lupei, E. A. Fidancev, G. Aka et al., "Spectroscopic and crystal field studies of $\mathrm{Nd}^{3+}$ in $\mathrm{GdCa}_{4} \mathrm{O}\left(\mathrm{BO}_{3}\right)_{3}$ and $\mathrm{YCa}_{4} \mathrm{O}\left(\mathrm{BO}_{3}\right)_{3}$," Physical Review B, vol. 65, 11 pages, 2002.

[30] R. Arun Kumar and R. Dhanasekaran, "Flux growth of yttrium calcium oxy borate (YCOB) single crystals for nonlinear optical applications," Journal of Crystal Growth, vol. 311, no. 3, pp. 541-543, 2009.

[31] R. Arun Kumar and R. Dhanasekaran, "Growth and characterization of LCOB and NdLCOB single crystals for laser applications," Journal of Crystal Growth, vol. 318, no. 1, pp. 636-641, 2011.
[32] F. Jing, P. Fu, Y. Wu, Y. Zu, and X. Wang, "Growth and assessment of physical properties of a new nonlinear optical crystal: lanthanum calcium borate," Optical Materials, vol. 30, no. 12, pp. 1867-1872, 2008.

[33] R. Guo, Y. Wu, P. Fu, and F. Jing, "Growth and spectroscopic properties of ytterbium-doped lanthanum calcium borate $\left(\mathrm{Yb}^{3+}: \mathrm{La}_{2} \mathrm{CaB}_{10} \mathrm{O}_{19}\right)$ crystal," Optics Communications, vol. 244, pp. 321-325, 2005. 

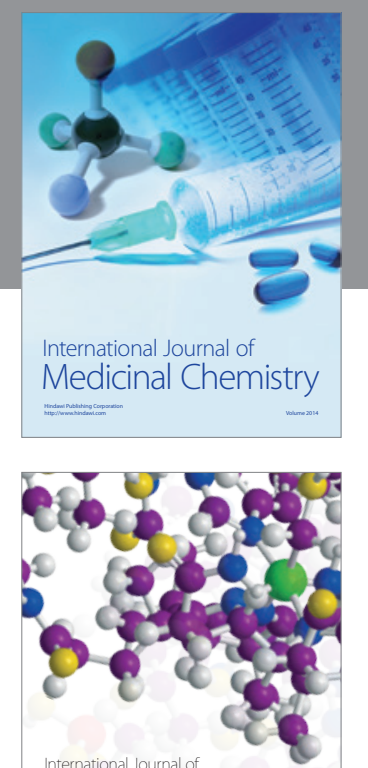

\section{Carbohydrate} Chemistry

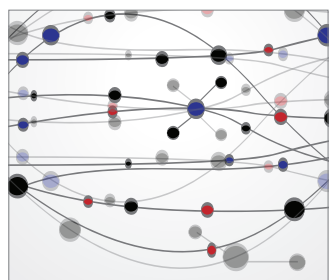

The Scientific World Journal
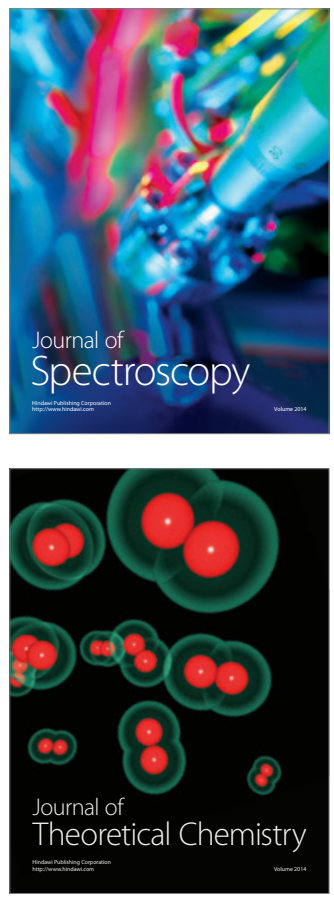
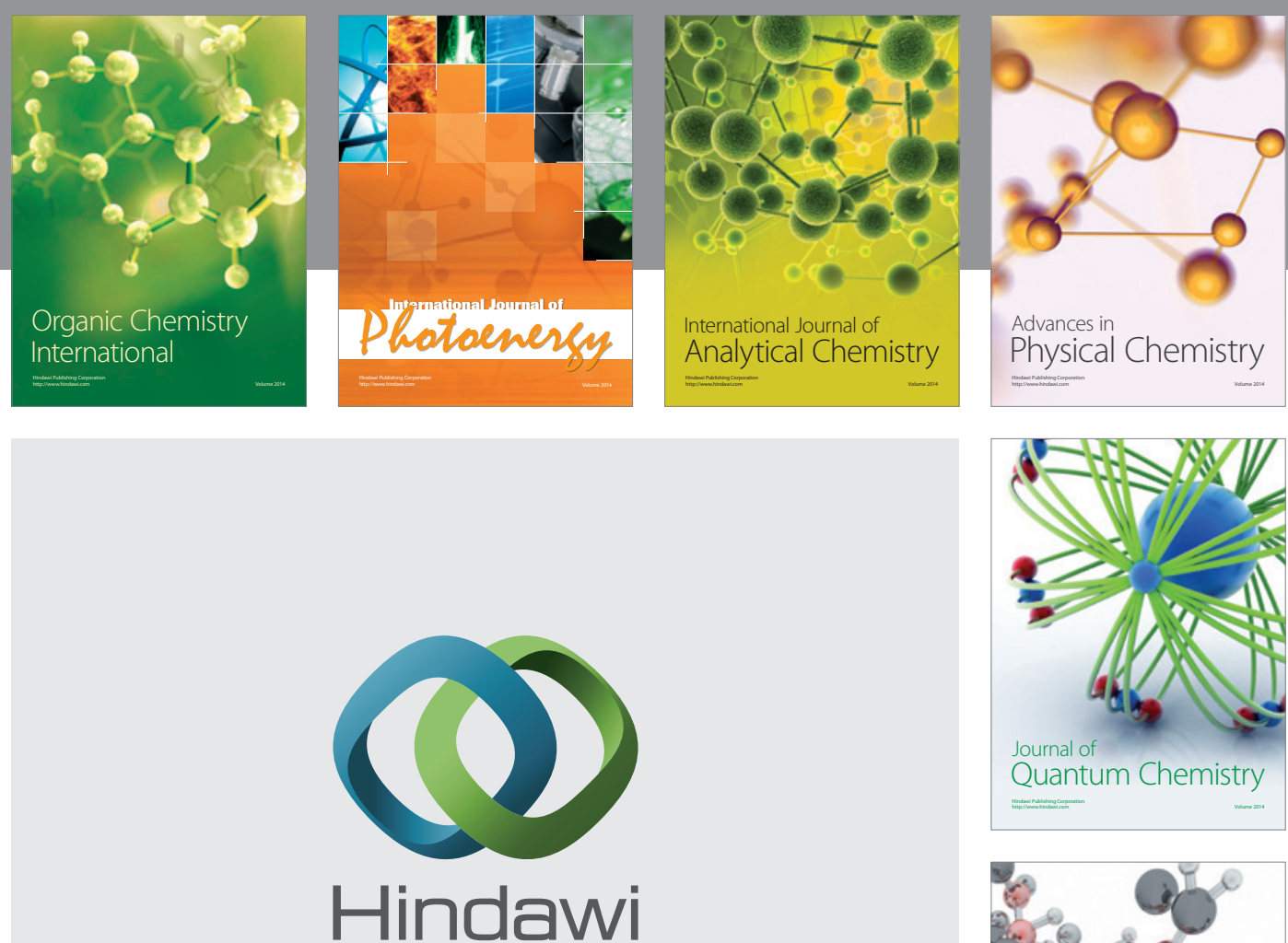

Submit your manuscripts at

http://www.hindawi.com

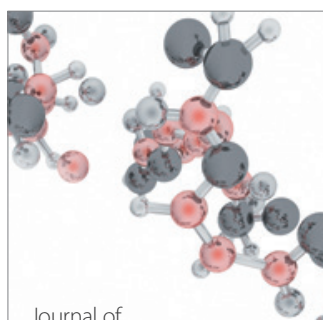

Analytical Methods

in Chemistry

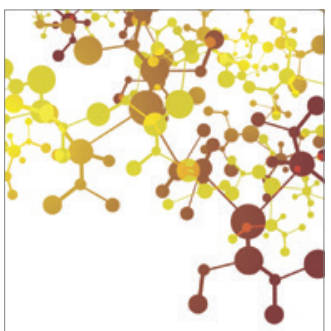

Journal of

Applied Chemistry

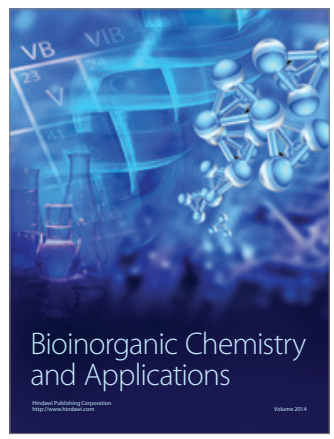

Inorganic Chemistry
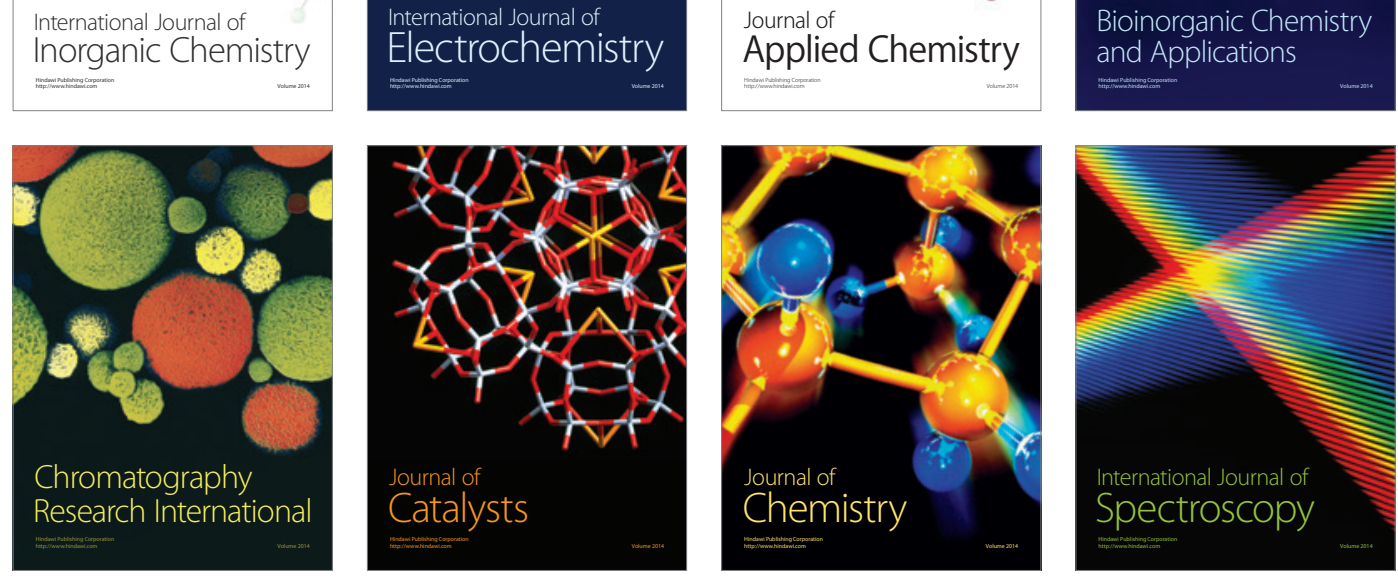